\title{
RBEP
}

\section{Perfil dos alunos internos no ensino profissional agrícola federal mantido pelo Ministério da Agricultura em Sergipe (1934-1967)}

Joaquim Tavares da Conceição $\mathrm{O}^{\mathrm{I}, \text { II }}$

http://dx.doi.org/10.1590/S2176-6681/346413576

\section{Resumo}

Aborda historicamente a condição socioeconômica dos alunos assistidos no internato da instituição de ensino profissional agrícola mantida pelo Ministério da Agricultura no estado de Sergipe, no período de 1934 a 1967. A operação historiográfica seguiu separando, reunindo e transformando em documentos históricos as informações coletadas. Foram manejadas fontes diversas, como relatórios, livros, imagens fotográficas, legislação, jornais e relatos de memórias. A pesquisa, recepcionando as contribuições de trabalhos sobre a história do ensino agrícola, procurou compreender o internato como uma marca significativa do ensino agrícola. Transparece, no decorrer do período pesquisado, especialmente da década de 1930 a meados de 1950, uma dualidade de atuação da instituição: a formação profissional agrícola e o assistencialismo mediante o internato público e gratuito.

Palavras-chave: internato; ensino agrícola; Sergipe; educação; história.

I Programa de Pós-Graduação em Educação da Universidade Federal de Sergipe (UFS), São Cristóvão, Sergipe, Brasil. E-mail: jtc@ufs.br

II Doutor em História pela Universidade Federal da Bahia (UFBA), Salvador, Bahia, Brasil. 


\section{Abstract \\ Profile of boarding students in federal professional agricultural education maintained by the Ministry of Agriculture in Sergipe (1934 - 1967)}

This article is a historical approach about the socioeconomic situation of boarding students assisted by the institution of agricultural professional education, maintained by the Ministry of Agriculture in the state of Sergipe, in the period between 1934 and 1967. The historiographical operation was made by separating, collecting and turning the collected information into historical documents. Different sources were managed, such as reports, books, photographic images, legislation, newspapers and memoirs reports. The research, receiving contributions of works about the history of agricultural education, sought to understand the boarding school as a significant mark of agricultural education. During the researched period, especially from the 1930's to the mid 1950's, there is evidence about a duality of roles played by the institution: the agricultural professional education and the welfare through free public boarding school.

Keywords: boarding school; agricultural education; Sergipe; education; History.

\section{Introdução}

Este artigo é uma análise histórica do perfil, da procedência e da condição socioeconômica dos alunos internos matriculados em uma instituição de ensino profissional agrícola federal fundada e mantida no estado de Sergipe (SE) - povoado Quissamã, município de São Cristóvão pelo Ministério da Agricultura, no período de 1934 a 1967. A origem dessa instituição remonta ao ano de 1924, quando foi fundado, pelo presidente do estado, Maurício Graccho Cardoso, o Patronato Agrícola São Maurício. Em 1934, o Patronato foi federalizado e passou a ser denominado de

No ano de 1967 , ocorreu a transferência do ensino agrícola e de toda a rede federal dos estabelecimentos desse ramo de ensino do Ministério da Agricultura para a competência do Ministério da Educação (Brasil, 1967). A partir de 1979, a instituição recebeu a denominação de Escola Agrotécnica Federal de São Cristóvão e, atualmente, é parte integrante do Instituto Federal de Sergipe (IFS), com a denominação de Campus São Cristóvão. Aprendizado Agrícola de Sergipe, sob a competência do Ministério da Agricultura. No período que compreende o recorte temporal deste trabalho (1934-1967), a instituição esteve vinculada ao Ministério da Agricultura e desenvolveu diversos modelos de ensino agrícola: aprendizado agrícola (1934-1947), escola de iniciação agrícola (1946-1952), escola agrícola (1952-1957), escola agrotécnica (1957-1964) e colégio agrícola (1964-1979). ${ }^{1}$

A problematização de questões relacionadas ao internamento escolar no contexto do ensino agrícola federal continua sendo uma "zona silenciosa". A pesquisadora Dagmar Zibas (1987) descreveu e analisou 
alguns dados obtidos por meio de estudo de caso do internato de duas escolas agrotécnicas, evidenciando problemas do sistema e considerando o internato como uma das questões mais negligenciadas dessas escolas. Esse estudo, ao tempo que evidenciava problemas semelhantes aos de outros estabelecimentos de ensino agrícola federal, apontava para a necessidade de uma investigação histórico-educacional das configurações históricas do internato nos estabelecimentos federais de ensino agrícola. Assim, o presente artigo, recebendo as contribuições de trabalhos sobre a história do ensino agrícola (Conceição, 2007; Mendonça, S., 1997; Nascimento, 2004; Nery, 2006), estabelece uma análise a respeito da clientela atendida no internato de uma instituição federal de ensino profissional agrícola. A pesquisa se enquadra no campo da história da educação, especificamente dentro dos trabalhos que adotam os pressupostos da história cultural, resultando em uma investigação histórica que se volta para indagações sobre aspectos internos da instituição escolar (Nunes, 1992; Souza, 1998).

Objetivou-se uma "história descontínua" (Le Goff, 2003), procurando ler e compreender as informações que os agentes quiseram registrar nos documentos analisados. Levou-se em conta que os "documentos" são repletos de significados e interesses, devendo ser analisados como um monumento, no sentido de que todo documento é uma "montagem" que deve ser esquadrinhada pelo historiador para entender a "imagem" que os agentes históricos quiseram nele representar, sobretudo, entendendo que

[...] o que sobrevive não é o conjunto daquilo que existiu no passado, mas uma escolha efetuada quer pelas forças que operam no desenvolvimento temporal do mundo e da humanidade, quer pelos que se dedicam à ciência do passado e do tempo que passa, os historiadores. (Le Goff, 2003, p. 525).

Nesse sentido, operou-se separando, reunindo e transformando em documentos históricos as informações ou os objetos coletados (Certeau, 2002).

Foram manejadas fontes diversas, devidamente agrupadas em duas categorias: documentos escritos e relatos de memória. As fontes escritas foram catalogadas e organizadas em: a) documentos da Escola Agrotécnica Federal de São Cristóvão - EAFSC-SE (relatórios anuais de diretores, livros manuscritos); b) documentos da República Federativa do Brasil (relatórios dos ministros da agricultura ao presidente da República, outros documentos produzidos pelo Ministério da Agricultura e pelo Ministério da Educação e a legislação sobre ensino agrícola e temas correlatos); c) documentos do estado de Sergipe (legislação, mensagens, ofícios e outros documentos produzidos pelo Poder Executivo estadual, processos judiciais e outros atos do Judiciário estadual); e d) jornais que circularam no período pesquisado. Dentro dessa diversidade de tipologia de fontes, o Livro de Matrícula do Aprendizado Agrícola de Sergipe (1938) se apresentou como um registro relevante para a caracterização socioeconômica dos internos. O livro apresenta uma escrituração com variados dados informativos sobre 210 
alunos internos na instituição entre os anos de 1937 e 1941. Com base na consulta desses dados, devidamente cotejados com as demais fontes examinadas, foi possível estabelecer características socioeconômicas dos internos atendidos na instituição no período em que funcionou como Aprendizado Agrícola.

A pesquisa das fontes escritas teve como lugar os arquivos da EAFSC-SE; a Coleção de Jornais do Arquivo Digital do Instituto Histórico e Geográfico de Sergipe (IHGS); o Sistema de Informações do Congresso Nacional (Sicon); a Biblioteca Nacional; o Arquivo Judiciário do Estado de Sergipe, especialmente no Fundo Aracaju/Juizado da Infância e Juventude e no Fundo São Cristóvão/SCR; e, ainda, na Biblioteca Pública Epifânio Dória (BPED).

As "memórias" foram coletadas por meio da técnica da entrevista dirigida com a utilização de um questionário ou roteiro, confeccionado a partir das evidências históricas preliminarmente encontradas nas fontes escritas ou em depoimentos anteriores. Levou-se em consideração que o grupo é suporte da memória, pois esta é coletiva, mas é o indivíduo que recorda. Cada grupo vive o tempo de forma diferente, como o tempo vivido no internato. Assim, por muito que se "deva à memória coletiva, é o indivíduo que recorda. Ele é o memorizador e das camadas do passado a que tem acesso pode tecer objetos que são, para ele, e só para ele, significativos dentro de um tesouro comum" (Bosi, 1994, p. 411).

Após a federalização, em 1934, a instituição passou a funcionar com o modelo de ensino agrícola profissional denominado aprendizado agrícola, e assim se manteve até 1946. Nessa fase, recebeu o nome inaugural de Aprendizado Agrícola de Sergipe (1934-1939) e depois de Aprendizado Agrícola Benjamin Constant, até o final do período (Brasil, 1934a, 1934b, 1939). Os aprendizados agrícolas (AA) faziam parte da estrutura organizacional do Ministério da Agricultura, por meio da Diretoria do Ensino Agrícola (DEA), subordinada ao Departamento Nacional da Produção Vegetal (Brasil, 1934b), e tinham como objetivo oficial "cooperar na educação das populações rurais", ministrando formação profissional agrícola de nível primário e formação complementar pela execução de trabalhos nas oficinas de madeira, ferro e couro. A organização dos aprendizados agrícolas deveria imitar uma fazenda moderna e produtiva para que esses estabelecimentos servissem de modelo pedagógico para os menores internados, futuros trabalhadores do campo (Conceição, 2007).

Com o advento da Lei Orgânica do Ensino Agrícola (Brasil, 1946), inaugura-se uma nova fase do ensino profissional agrícola. Essa lei estabeleceu uma completa regulamentação do ensino agrícola no País, determinando que passasse a ser ministrado em dois ciclos, cada um formado por dois cursos. O Quadro 1 explicita como ficou essa regulamentação a partir da citada lei: 
Quadro 1 - Ciclos, Cursos, Formação e Tipos de Estabelecimento de Ensino Agrícola Profissional - 1946-1961*

\begin{tabular}{|c|c|c|}
\hline \multicolumn{3}{|c|}{$1^{\circ}$ ciclo de formação } \\
\hline Curso & Formação & Tipo de estabelecimento \\
\hline Iniciação agrícola & Operário agrícola & $\begin{array}{c}\text { Escola de iniciação agrícola, } \\
\text { Colégio agrícola ou escola } \\
\text { agrotécnica }\end{array}$ \\
\hline Mestria agrícola & Mestre agrícola & $\begin{array}{c}\text { Colégio agrícola ou escola } \\
\text { agrotécnica }\end{array}$ \\
\hline \multicolumn{3}{|c|}{$2^{\circ}$ ciclo de formação } \\
\hline Curso & Formação & Tipo de estabelecimento \\
\hline Agrícola técnico & Técnico agrícola & \multirow{2}{*}{ Escola agrotécnica } \\
\hline $\begin{array}{c}\text { Agrícola } \\
\text { pedagógico }\end{array}$ & $\begin{array}{c}\text { Docente para ensino } \\
\text { agrícola }\end{array}$ & \\
\hline
\end{tabular}

Fonte: Brasil (1946).

* Conforme o Decreto-Lei no 9.613 de 1946.

A Lei Orgânica do Ensino Agrícola também determinava que os cursos de formação deveriam se articular entre si, de modo que os alunos pudessem progredir de um a outro, segundo a sua vocação e capacidade. Assim, o curso de iniciação agrícola estaria articulado com o ensino primário, e os cursos agrícolas técnicos e o Curso de Magistério de Economia Doméstica Agrícola, com o ensino secundário e o ensino normal do primeiro ciclo (Brasil, 1946). A lei igualmente conferia ao diplomado em um curso agrícola técnico o direito de ingressar em estabelecimentos de ensino superior, mas, para isso, era preciso que o curso superior fosse diretamente relacionado com o curso agrícola técnico concluído e que o candidato se submetesse às condições de admissão de acordo com a legislação pertinente ao ensino superior.

A Lei Orgânica do Ensino Agrícola também estabeleceu três classificações ou tipos de estabelecimentos de ensino agrícola: "escola de iniciação agrícola", "escola agrícola" e "escola agrotécnica". Cada instituição era classificada em um desses tipos, conforme suas condições para ministrar os respectivos cursos de formação. Os novos enquadramentos dos estabelecimentos federais de ensino agrícola foram regulamentados pelo Decreto $\mathrm{n}^{\circ}$ 22.506, de 22 de janeiro de 1947. O Quadro 2 apresenta o cenário nacional da rede federal de estabelecimentos de ensino agrícola, consoante as transformações de tipo de estabelecimento. 


\section{Quadro 2 - Rede Federal dos Estabelecimentos de Ensino Agrícola Profissional - Localização e Mudanças de Tipo de Estabelecimento - 1947}

\begin{tabular}{|c|c|c|}
\hline \multirow[b]{2}{*}{$\begin{array}{l}\text { Localização } \\
\text { (estado) }\end{array}$} & \multirow[b]{2}{*}{$\begin{array}{l}\text { Tipo de estabelecimento até } \\
1947\end{array}$} & $\begin{array}{l}\text { Novo enquadramento } \\
\text { do estabelecimento }\end{array}$ \\
\hline & & $\begin{array}{l}\text { Fundamentação legal: } \\
\text { Decreto-Lei nº 9.613/46 c/c } \\
\text { Decreto n }{ }^{\circ} 22.506 / 47\end{array}$ \\
\hline Minas Gerais & Escola Agrícola de Barbacena & Escola Agrotécnica de Barbacena \\
\hline Paraíba & Aprendizado Agrícola Vidal de Negreiros & $\begin{array}{l}\text { Escola Agrotécnica Vidal de } \\
\text { Negreiros }\end{array}$ \\
\hline Rio Grande do Sul & Aprendizado Agrícola Visconde da Graça & $\begin{array}{l}\text { Escola Agrotécnica Visconde da } \\
\text { Graça }\end{array}$ \\
\hline Pernambuco & Aprendizado Agrícola João Coimbra & Escola Agrícola João Coimbra \\
\hline Alagoas & Aprendizado Agrícola Floriano Peixoto & Escola Agrícola Floriano Peixoto \\
\hline Rio de Janeiro & Aprendizado Agrícola Nilo Peçanha & Escola Agrícola Nilo Peçanha \\
\hline Rio de Janeiro & Aprendizado Agrícola Ildelfonso Simões Lopes & $\begin{array}{l}\text { Escola Agrícola Ildelfonso Simões } \\
\text { Lopes }\end{array}$ \\
\hline Sergipe & Aprendizado Agrícola Benjamim Constant & $\begin{array}{l}\text { Escola de Iniciação Agrícola } \\
\text { Benjamim Constant }\end{array}$ \\
\hline Bahia & Aprendizado Agrícola Sérgio de Carvalho & $\begin{array}{l}\text { Escola de Iniciação Agrícola Sérgio } \\
\text { de Carvalho }\end{array}$ \\
\hline Minas Gerais & Aprendizado Agrícola Visconde de Mauá & $\begin{array}{l}\text { Escola de Iniciação Agrícola } \\
\text { Visconde de Mauá }\end{array}$ \\
\hline Mato Grosso & Aprendizado Agrícola Gustavo Dutra & $\begin{array}{l}\text { Escola de Iniciação Agrícola Gustavo } \\
\text { Dutra }\end{array}$ \\
\hline Pará & Aprendizado Agrícola Manuel Barata & $\begin{array}{l}\text { Escola de Iniciação Agrícola Manuel } \\
\text { Barata }\end{array}$ \\
\hline Amazonas & Aprendizado Agrícola Rio Branco & $\begin{array}{l}\text { Escola de Iniciação Agrícola do } \\
\text { Amazonas }\end{array}$ \\
\hline Território do Acre & Escola de Iniciação Agrícola Rio Branco (criad & m 1946 pelo Decreto-Lei no 9.758/46) \\
\hline
\end{tabular}

Fonte: Brasil (1946, 1947).

Nesse contexto de mudanças, o estabelecimento de ensino agrícola fundado em Sergipe, sempre mantendo o regime de internato, foi paulatinamente sendo enquadrado nos diversos tipos de estabelecimentos de ensino agrícola previstos pela legislação.

A Lei de Diretrizes e Bases da Educação (LDB) de 1961 (Brasil, 1961) revogou a Lei Orgânica do Ensino Agrícola e passou a regular o ensino agrícola profissional. Mais uma vez um decreto tratou de fazer a adequação dos estabelecimentos de ensino agrícola à nova legislação (Brasil, 1964). Com esse decreto, a instituição foi transformada de escola agrotécnica em colégio agrícola e, consequentemente, autorizada a ministrar o ensino 
profissional agrícola, em todos os seus níveis, articulado com o ensino secundário. A LDB classificou o ensino agrícola, ao lado do industrial e do comercial, como curso técnico, ministrado em dois ciclos: o primeiro era o ginasial, com a duração de quatro anos, e o segundo, o colegial, com o mínimo de três anos. Com a nova legislação, os colégios agrícolas podiam expedir certificados de ensino médio que possibilitavam ao concluinte concorrer à admissão em qualquer curso superior.

O Quadro 3 mostra a evolução histórica da instituição de acordo com as mudanças operadas pelas leis que regulamentaram o ensino agrícola no período em estudo.

\section{Quadro 3 - Configurações da Instituição Ensino Agrícola Federal em Sergipe - Tipos de Estabelecimento e Modelos de Ensino - 1934-1967}

\begin{tabular}{|c|c|c|c|}
\hline \multirow[b]{2}{*}{ Tipo de estabelecimento } & \multirow[b]{2}{*}{ Período } & \multicolumn{2}{|c|}{ Modelo de ensino } \\
\hline & & $\begin{array}{c}\text { Ensino profissional } \\
\text { agrícola }\end{array}$ & Ensino propedêutico \\
\hline Aprendizado Agrícola de Sergipe & 1934-1939 & \multirow{2}{*}{ Curso agrícola básico } & \multirow{2}{*}{ Curso primário } \\
\hline $\begin{array}{l}\text { Aprendizado Agrícola Benjamin } \\
\text { Constant }\end{array}$ & 1939-1946 & & \\
\hline $\begin{array}{l}\text { Escola de Iniciação } \\
\text { Agrícola Benjamin } \\
\text { Constant }\end{array}$ & 1946-1952 & Curso de iniciação agrícola & Curso primário \\
\hline $\begin{array}{l}\text { Escola Agrícola Benjamin } \\
\text { Constant }\end{array}$ & 1952-1957 & $\begin{array}{l}\text { Curso de iniciação agrícola } \\
\text { Curso de mestria agrícola }\end{array}$ & $\begin{array}{l}\text { Ensino secundário (curso } \\
\text { ginasial) }\end{array}$ \\
\hline $\begin{array}{l}\text { Escola Agrotécnica } \\
\text { Benjamin Constant }\end{array}$ & 1957-1964 & $\begin{array}{l}\text { Curso de iniciação agrícola } \\
\text { Curso de mestria agrícola } \\
\text { Curso técnico agrícola }\end{array}$ & $\begin{array}{l}\text { Ensino secundário (cursos } \\
\text { ginasial e colegial) }\end{array}$ \\
\hline $\begin{array}{l}\text { Colégio Agrícola Benjamin } \\
\text { Constant }\end{array}$ & 1964-1979 & $\begin{array}{l}\text { Curso de iniciação agrícola } \\
\text { Curso de mestria agrícola } \\
\text { Curso técnico agrícola }\end{array}$ & $\begin{array}{l}\text { Ensino médio (cursos } \\
\text { ginasial e colegial) }\end{array}$ \\
\hline
\end{tabular}

Fonte: Brasil (1934a, 1934b, 1939, 1943, 1946, 1947, 1952, 1957, 1961, 1964).

Diante de todas as mudanças quanto ao tipo de estabelecimento e ao modelo de ensino, a instituição de ensino profissional agrícola fundada em Sergipe, no período de 1924 a 1967, sempre manteve o internato público masculino como uma característica que acompanhou sua história.

\section{Internato público e gratuito: os bens e serviços disponibilizados aos internos}

Nos internatos dos estabelecimentos federais de ensino agrícola, no período compreendido na periodização deste artigo, basicamente eram disponibilizados aos internos, sem a cobrança de mensalidades ou qualquer 
tipo de custo, espaço determinado no dormitório com a respectiva cama e colchão, enxoval (fardas e roupas de cama), alimentação e cuidados com higiene e saúde. A manutenção do internato público e gratuito era garantida pelos recursos financeiros destinados à instituição pelo Ministério da Agricultura (MA), por meio da Superintendência de Ensino Agrícola e Veterinário (Seav) e da receita própria resultante da produção dos núcleos agropecuários da instituição.

O sistema de gratuidade adotado nos estabelecimentos de ensino agrícola (Brasil, 1946) estava dentro da política do Ministério da Agricultura, que visava direcionar esse ramo do ensino, principalmente o nível elementar, para a população pobre da zona rural (Tôrres Filho, 1926).

A instituição aqui pesquisada, como parte dessa rede de estabelecimentos, caracterizou-se pelo oferecimento de bens e serviços sem custos para os internos. Primeiramente, era disponibilizada a utilização dos espaços específicos do internato (dormitório, refeitório e instalações sanitárias), todos de uso coletivo. O alojamento era garantido pela disposição de um local específico no dormitório coletivo com cama e colchão. Os internos também recebiam um enxoval que, com algumas variações ocorridas durante o período, referentes à quantidade de itens e a tipos ou modelos, era composto por fardas, calçados, roupas de cama e material para higiene pessoal. A alimentação igualmente era disponibilizada sem custos aos internos durante todo o período. Práticas de higienização e cuidados com a saúde também foram serviços oferecidos aos internos, os quais, quando chegavam à instituição, eram obrigados a conviver com as regras higiênicas impostas e fiscalizadas pela equipe dirigente.

\section{Aprendizado agrícola: "casa de amparo ou assistência ao menor pobre"?}

O Aprendizado Agrícola, como era conhecida a instituição de ensino profissional agrícola mantida em Sergipe pelo Ministério da Agricultura, no período de 1934 a 1967, assistiu no internato em torno de 4.935 alunos. Esses internos eram todos do sexo masculino, pobres, originários de famílias de trabalhadores rurais e urbanos e pequenos lavradores. Até meados da década de 1950, o internamento desses alunos era realizado por solicitação dos familiares - pais, irmãos, tios, tutores - e de sacerdotes católicos e por requisição de juízes de menores e autoridades do Serviço de Menores. O relato do senhor Manuel do Carmo Santos (2005), conhecido como "Manuel Carpinteiro", é elucidativo de como menores eram enviados à instituição nas décadas de 1930-1940. Órfão de mãe, foi internado no ano de 1935 no Aprendizado Agrícola de Sergipe juntamente com o seu irmão, Fernando do Carmo Santos, por intermédio do monsenhor Carlos Cruz, arcebispo de Aracaju na época.

O estudo eu fui para o Aprendizado quando eu perdi minha mãe. Em 1935 no Aprendizado Agrícola naquela época. José Augusto de Lima 
era o diretor. Era bom sujeito. Pai da pobreza. Naquele tempo o pobre ia pra lá. Eu fui por intermédio do Monsenhor Carlos. A gente ia pra lá como se fosse, como se fosse filho sem pai, como se fosse orfanato. (Santos, M., 2005).

Predominou nos anos de 1930 e 1940, principalmente pela assistência que proporcionava por meio do internato, o costume de recorrer ao Aprendizado Agrícola como uma instituição de amparo às camadas pobres da população (Bandeira, 1989; Brasil. Ministério da Agricultura, 1935, 1938b; Sergipe, 1938). Assim, era bastante ressaltada nas notas dos visitantes da instituição, grafadas no Livro de registro de impressões dos visitantes, a representação do estabelecimento como primordialmente de amparo aos pobres. Nessas notas, para caracterizar os internos atendidos pela instituição, era recorrente o uso de termos como "infância desamparada", "meninos pobres", "gerações proletárias", "infância desvalida", "jovens desprotegidos da fortuna" (Brasil. Ministério da Agricultura, 1935). Gervásio de Carvalho Prata, desembargador do Tribunal de Justiça de Sergipe na época, foi um dos visitantes que se reportou à instituição como uma obra de amparo aos pobres. Em uma de suas visitas, em 20 de dezembro de 1942, grafou no livro sua nota de impressão sobre o estabelecimento. Em trecho da nota, escreveu: "Menciono nestas ínfimas linhas o meu louvor ao Aprendizado Agrícola de Sergipe, onde são incluídos os meninos pobres que nele encontram instrução, educação e trabalho, para se tornarem úteis à Nação" (Brasil. Ministério da Agricultura, 1935, p. 14).

Dos 77 visitantes que deixaram suas notas de impressões no Livro de registro das impressões dos visitantes, no período de 1935 a 1944, apenas um destacou uma mudança no perfil do estabelecimento de instrução premonitória para um estabelecimento essencialmente de formação profissional agrícola:

De simples Patronato Agrícola que foi fruto da iniciativa do antigo e grande Presidente deste Estado, o ilustre Dr. Mauricio Graccho Cardoso, passou este estabelecimento de instrução premonitória da juventude a uma escola de maior eficiência, qual a que decorre do ensino agrícola neste país essencialmente agrícola. (Brasil. Ministério da Agricultura, 1935, p. 10).

De fato, embora o objetivo principal da instituição fosse a formação profissional agrícola, ficou evidenciado nas fontes analisadas que famílias pobres se apropriaram da escola também como um recurso para fugir da pobreza a que se viam relegadas (Bandeira, 1989; Brasil. Ministério da Agricultura, 1938b, 1935). O agrônomo Astolfo Ribeiro Pinto Bandeira, que dirigiu a instituição de 1945 a 1947, expôs em suas memórias essa situação. Segundo esse diretor, os "menores ali internados eram, em sua grande maioria, procedentes de famílias pobres, que os colocavam, com o fim de solucionarem, em parte, os seus problemas domésticos" (Bandeira, 1989, p. 10). Igualmente, no relato de José Gregório, ex-interno da instituição na década de 1940 e procedente da zona rural do município de Cedro de São João-SE, essa ocorrência também é manifesta: 
Eu não tinha condições porque o estudo tinha que sair para uma outra cidade [...]. Eu trabalhava na agricultura junto com os velhos. Não tinha outra atividade. [...] Minha mãe se interessou. Os adolescentes, a maioria vinha pra o Aprendizado. Era uma escola feita pra o pobre, o pobre que não podia estudar fora. Então tirava a papelada nos cartórios e então entrava. Ia começar a vida. A decisão foi da minha mãe. Ela disse: "Eu vou colocar vocês lá pro Aprendizado porque aqui não tem meio, vocês aqui vão se acabar". Porque não havia mesmo, outro jeito melhor, um futuro pra uma criança. Então colocou a gente pra lá. Cheguei no início do ano de 1943. Era uma escola que ensinava e onde se trabalhava. (Gregório, 2005).

O estudo de uma relação de 210 internos registrados no Livro de Matrícula do Aprendizado Agrícola de Sergipe, entre os anos de 1937 e 1941, ajuda na confirmação da caracterização da pobreza dos internos. Dos 210 internos registrados no livro de matrícula, 73 eram órfãos, sendo 45 órfãos de pai, 18 de mãe e 10 de pai e mãe. Além do grande percentual de órfãos, existiam os filhos de "pai desconhecido". Os pais e mães de órfãos e as mães solteiras internavam seus filhos provavelmente por não terem condições financeiras de criá-los e verem a instituição como um recurso para a pobreza. Somava-se, ainda, o predomínio de 170 internos de origem negra, sendo 111 "morenos", 49 "pretos" e 10 "pardos". Apenas 40 internos foram declarados como "brancos". Quanto ao grau de instrução, 25 eram analfabetos e o restante sabia rudimentos da leitura e da escrita. A idade dos internos variava de 9 a 14 anos (Brasil. Ministério da Agricultura, 1938b). Esses dados quantitativos analisados em conjunto com os dados qualitativos anteriormente indicados possibilitam afirmar que os internos matriculados no estabelecimento, especialmente na época que funcionou como Aprendizado Agrícola (1934-1946), eram pobres, muitos dos quais órfãos ou filhos de "pai desconhecido", e a maioria de descendência negra.

O diretor do Serviço Social de Menores, na visita que fez à instituição no ano de 1939, ainda grafando em sua nota de impressão a denominação do estabelecimento como patronato, destacou a cooperação que o estabelecimento, mediante seu diretor, na época o agrônomo José Augusto de Lima, prestava ao mencionado serviço de assistência, evidentemente acolhendo menores enviados pela repartição. Assim, registrou no livro de impressões o citado diretor:

Após a visita que fiz a este "patronato", externo, com prazer, a agradável impressão que me causou. Por certo o Dr. José Augusto de Lima, que o dirige, tem uma parte principal na obra que aqui se realiza e que, em outro setor, tanto interessa o atual governo do Estado. Com mais amplos recursos, sem dúvida nenhuma, maior seria o resultado obtido. A minha visita, por sua vez é um resultado da cordialidade do seu operoso diretor para com o Chefe do Serviço de Menores de Sergipe, convencido que o trabalho em prol da criança deve estar submetido a uma estreita e inteligente cooperação. (Brasil. Ministério da Agricultura, 1935, p. 10).

Esse reconhecimento da instituição como uma obra de "assistência aos pobres", por meio da qual a sociedade sergipana a enxergava, decorria da herança dos tempos em que ela funcionou como Patronato Agrícola (1924-1934) e tinha como objetivo "assistir os menores desvalidos" (Nery, 
2006). Apesar da mudança de nome e de seus objetivos, o estabelecimento continuava sendo procurado como se fosse uma casa de "assistência social". Assim, o acolhimento no internato era o grande fator de atração para os que buscavam a escola até meados de 1950. Ainda no ano de 1952, o diretor João Fernandes de Souza (1949-1953) destacava outra herança da época em que a escola funcionou como Patronato Agrícola: a utilização que a sociedade continuava fazendo da instituição como uma "casa de correção" disciplinar. Segundo o diretor:

A atual escola teve a sua origem de um Patronato (Reformatório de Menores), atualmente acha-se engradada na legislação como estabelecimento de ensino secundário de primeiro ciclo. Aos antigos pais de alunos e aos moradores da região esta escola não sofreu evolução, mandam para lá os seus filhos-problemas, supondo tratar-se ainda de uma casa de correção [...]. Portanto a esses resíduos sociológicos não cabiam matrícula num estabelecimento de ensino que não tem bases correcionais. (Sergipe, 1953, p. 19).

Dessa maneira, além de recorrerem ao estabelecimento como solução para a condição de pobreza, muitas famílias e provavelmente autoridades internavam meninos a fim de serem corrigidos os defeitos da primeira educação. Continuavam, inclusive, designando a instituição de patronato, como se não tivessem ocorrido mudanças em seus objetivos. Segundo o diretor-agrônomo João Fernandes de Sousa, essa era uma das razões do aparecimento no internato de meninos indisciplinados, aos quais a direção lançava mão de "todos os princípios educacionais que conhece a fim de poder melhor integrar à sociedade um homem capaz de lhe ser útil" (Sergipe, 1953, p. 19). Os meios para atingir esse desiderato incluíam os castigos físicos (Conceição, 2007).

A professora Cacilda de Oliveira Barros, que visitou a instituição na década de 1930, na época em que esta funcionou como Aprendizado Agrícola, embora se refira à instituição como patronato, também ressalta o perfil de pobreza dos internos e a utilização do estabelecimento como um lugar para corrigir:

\footnotetext{
Eu, quando criança, certa feita fui lá, mas recordo que saí muito mal impressionada. Ainda era o patronato. Eu era menina, eu fui com a minha mãe e uma amiga dela visitar um menino. Foi a pior impressão. Porque os meninos eram vestidos de macacão, maltratadinhos. As instalações eram precárias, mas o prédio central existia. Pra lá iam as crianças que os pais não tinham certo domínio. Era quase como um castigo. Eles iam pra lá, faziam trabalho forçado. (Barros, 2006).
}

Também foi um fator importante para a formação desse perfil de pobreza dos internos a política do Ministério da Agricultura e o "discurso ruralista" que vinham se desenvolvendo desde o início do século 20, os quais defendiam as populações rurais pobres como público-alvo dos estabelecimentos de ensino agrícola profissional (Mendonça, S. 1997). Igualmente, a exaltação à vida no campo influenciou as políticas governamentais que diziam respeito diretamente ao meio rural e à educação dos seus habitantes. Tratava-se de discursos de agentes de diversas áreas 
intelectuais e políticos que exaltavam a vida no campo como estratégia de combate ao urbanismo provocado pelo êxodo rural e o desenvolvimento da educação rural: movimento denominado de "ruralismo pedagógico" (Nagle, 1974). Nesse contexto, a escola rural deveria

propagar as noções que correspondem às necessidades sociais e econômicas da população rural, levantar o prestígio da profissão agrícola, fazendo ver que a cultura da terra é um trabalho honroso e de intensa intelectualidade, despertando e fomentando nas crianças o amor à vida campestre e prática das nobres tarefas de valorização do solo. (Moraes, 1997, p. 195).

A despeito de ter sido um movimento mais preocupado com o avanço do ensino primário rural, o discurso ruralista encontrou em agentes defensores do desenvolvimento do setor agrário pelo ensino agrícola suas formas próprias de atuação. Sonia Regina de Mendonça (1997), estudando o ruralismo como "um movimento político de organização e institucionalização de interesses de determinadas frações da classe dominante agrária no Brasil", apresenta o ensino agrícola, especialmente o dedicado às classes subalternas, como uma das vertentes do ruralismo que "depositava na educação as possibilidades de recuperação do homem do campo e, por extensão, da própria agricultura brasileira" pela "disciplinarização da mão de obra" nos estabelecimentos de ensino agrícola profissional de grau elementar e médio (Mendonça, S. 1997).

O agrônomo Artur Torres Filho foi um dos agentes do movimento ruralista que depositava essa esperança no ensino agrícola. Durante boa parte da primeira metade do século 20, tendo como um dos veículos de sua fala a Revista Brasileira de Estudos Pedagógicos (Rbep), exaltou esse ramo do ensino profissional. Para ele, era

indispensável desenvolver o ensino profissional agrícola condizente com as necessidades do Brasil, por quanto os mais sérios problemas econômicos, aqueles de que depende a técnica da produção, só poderão ser alcançados por um ensino agrícola capaz de formar homens competentes em todos os ramos de aplicação da ciência agronômica, desde os mais complexos aos mais simples, formando-se um corpo de profissionais aptos a resolver todas as nossas questões de agronomia, tanto nos laboratórios como nas aplicações práticas. (Torres Filho, 1952, p. 118).

Esses discursos tiveram ressonância no Ministério da Agricultura. Como resultado, o ensino agrícola foi totalmente reestruturado no Brasil pelo advento da Lei Orgânica do Ensino Agrícola (Brasil, 1946), e seus estabelecimentos passaram a receber investimentos importantes ao longo das décadas seguintes, adequando seus espaços físicos para a oferta de mais vagas no internato.

A política do Ministério da Agricultura, que visava direcionar o ensino agrícola elementar para as populações rurais pobres, também contribuiu para estabelecer o perfil de pobreza dos internos matriculados nos estabelecimentos federais de ensino agrícola. Desse modo, nos relatórios anuais dos ministros da agricultura ao presidente da República, estes apresentavam os Aprendizados Agrícolas como estabelecimentos 
destinados aos "filhos de trabalhadores, operários rurais e pequenos lavradores" (Brasil. Ministério da Agricultura, 1939, p. 120). Por outro lado, segundo Torres Filho (1926), uma das vozes do ruralismo brasileiro, o problema agrário do Brasil, caracterizado pelo emprego de técnicas rudimentares e pela deficiência de mão de obra especializada, deveria ser debelado pela difusão da "agricultura científica," por meio do ensino agrícola que preparasse o trabalhador do campo e a retenção do seu deslocamento para os centros urbanos; medidas que, segundo ele, seriam atingidas com a oferta do ensino agrícola prioritariamente voltada para a população rural e pobre (Torres Filho, 1926).

Desse modo, o Ministério da Agricultura promoveu uma política de assistência integral aos alunos internados nos Aprendizados Agrícolas. No internato, eles recebiam, sem custos, alojamento, alimentação, enxoval, assistência médico-odontológica, entre outros bens e/ou serviços. Essa política adotada pelo Ministério procurou atender às peculiaridades dos estabelecimentos de ensino agrícola, ou seja, localização do estabelecimento escolar na zona rural, ensino em tempo integral e atendimento prioritário de uma clientela pobre que recorria a essas instituições educacionais (Conceição, 2007). O crescimento da oferta e da demanda pelo ensino agrícola esteve diretamente relacionado às possibilidades de oferta do internato. O oferecimento de vagas crescia de acordo com os investimentos nos espaços específicos do internato, especialmente a disponibilidade maior da taxa de ocupação dos dormitórios (Conceição, 2007).

\section{Variações no perfil dos internos}

A assistência que a instituição prestava aos seus alunos por meio do internato público e gratuito continuava como um forte atrativo para as famílias também nas décadas de 1950 e 1960. É elucidativa, mais uma vez, a descrição da professora Cacilda de Oliveira Barros a respeito dos internos que adentravam a instituição nesse período: "Eram todos do interior, e a condição social era baixa e muito baixa [...]. Eram umas crianças tristes. Eu posso dizer que todos do interior. Todos eram internos" (Barros, 2006).

O professor José Antônio Nunes Mendonça, em sua Análise quantitativa e qualitativa do sistema educacional do estado de Sergipe (1959), no tópico sobre ensino agrícola, comentando sobre a pouca expressividade desse ramo de ensino em Sergipe em comparação com os outros ramos do ensino profissional, destaca que a clientela dos estabelecimentos de ensino agrícola era atraída pela oferta do internato. Afirma, ainda, que no final da década de 1950 a instituição aqui pesquisada constituía-se "pelos aspectos da procura, ora como uma espécie de instituição para menores desamparados, ora como uma instituição de educação emendativa" (Mendonça, N., 1959, p. 12).

No entanto, a análise de alguns fatores indica que essas características, embora ainda estivessem presentes, encontravam-se em processo de transformação, a partir da década de 1950, provocado pela crescente procura por parte também das camadas médias da população (filhos de 
médios proprietários rurais, pequenos comerciantes, funcionários públicos etc.).

É necessário considerar nesta análise que a variação no perfil socioeconômico dos internos, ocorrida a partir da década de 1950, foi determinada, em parte, pelas mudanças nas modalidades e/ou nos níveis de ensino oferecidos pela instituição. Assim, a partir do ano de 1952, com o enquadramento do estabelecimento em Escola Agrícola, este ficou habilitado a ministrar o ensino profissional agrícola conjugado com o curso ginasial, o que provocou uma maior demanda de famílias que procuravam ginásios para matricular seus filhos.

Igualmente, foi um fator de atração de alunos ao estabelecimento o enquadramento, em 1957, da instituição em Escola Agrotécnica e, por conseguinte, o funcionamento, a partir de 1958, do curso técnico agrícola de nível médio em concomitância com o colegial do ensino secundário, que conferia ao diplomado o direito de concorrer ao curso do ensino superior relacionado com o curso agrícola (Brasil, 1946). Finalmente, em 1964, a instituição foi enquadrada como Colégio Agrícola e estava habilitada a expedir certificados de ensino médio que possibilitavam ao concluinte concorrer à admissão em qualquer curso superior. Dessa maneira, a instituição tornava-se duplamente atrativa, oferecia àqueles que não encontravam vagas nos poucos ginásios e colégios públicos existentes no estado, ou que não podiam custear as mensalidades em um ginásio ou colégio particular, o curso ginasial e a possibilidade de continuar no próprio estabelecimento para fazer o curso técnico colegial em um internato totalmente gratuito, com validade para a admissão em curso superior. Na década de 1950 e no início da década de 1960, a imprensa registrava a situação das vagas insuficientes nas escolas públicas e a carestia dos ginásios e colégios particulares como problemas enfrentados pelas famílias que desejavam que seus filhos continuassem os estudos. Situação também ressaltada por Acival Gomes dos Santos, filho de funcionário público municipal, ex-interno na década de 1960: "Como eu não podia vir estudar em colégios particulares, me manter aqui em Aracaju, a opção foi estudar no Colégio Agrícola" (Santos, A. G., 2006).

Assim, a procura pelo curso ginasial e depois pelo colegial, mais do que especificamente a formação agrícola, sem fazer desaparecer o predominante perfil de pobreza dos internos, começava a criar significativas mudanças na clientela atendida pela instituição:

Os colégios agrícolas estavam deixando de ser instituições destinadas quase que exclusivamente a alunos pobres. Muitos filhos da burguesia agrária estavam se tornando alunos do Colégio Agrícola. A instituição se constituía então numa boa alternativa de formação em nível médio, uma vez que além de contar com equipamento sofisticado e instalações experimentais e laboratoriais especializadas, também oferecia excelentes possibilidades de acesso ao ensino superior nas faculdades de Agronomia e de Medicina Veterinária. Por isto, não apenas pessoas pobres demandavam o Colégio naquele período, mas também grandes proprietários rurais e amplos contingentes de filhos dos setores médios e urbanos. (Nascimento, 2004, p. 221). 
Entretanto, à medida que os egressos da escola, especialmente a partir da implantação do curso técnico agrícola, iam galgando bons postos profissionais nos órgãos e nas empresas públicas federais, estaduais e municipais e na iniciativa privada, em atividades direta ou indiretamente relacionadas com a formação agrícola da qual eram portadores, a busca de uma condição objetiva de conseguir uma futura ocupação profissional tornava-se também um fator significativo de atração ao estabelecimento:

Meus conterrâneos chegavam nas férias muito felizes e seguros com um futuro. Os que estavam no último ano, no terceiro ano técnico, pareciam uns doutores formandos. [...] E me diziam que, já no segundo ano, estava encomendado o emprego deles, dizia que as empresas da Bahia mandavam procurar um número de técnicos superior aos formados na escola. (Santos, J. C., 2006).

A instituição começava a ser vista como um recurso para jovens do interior do estado, das camadas inferiores ou médias da população, que desejavam uma formação técnico-agrícola a fim de conseguirem uma ocupação profissional e melhorarem as condições de sobrevivência, conforme ressaltou Ademilson Vieira Santos, aluno interno da instituição de 1961 a 1967:

A escola representou tudo na minha vida. Porque filho de pescador, mãe doméstica, sete irmãos, e você sai da cidade do Cedro que não oferecia muitas coisas. A gente sai com o objetivo de ajudar a família. Eu tive essa oportunidade e logo comecei a trabalhar e ajudar os meus pais e irmãos. (Santos, A. V., 2006).

No final do ano de 1967, a imprensa noticiava a dificuldade de a escola responder à demanda de jovens do interior do estado em busca de uma formação técnica de nível médio (Agrotécnica..., 1967). No entanto, foi na década de 1950 que se acentuou o aumento do número das matrículas do estabelecimento iniciado no final da década de 1940. Além do progressivo crescimento do número de alunos a partir do decênio 1950, a maior procura pela instituição pode ser verificada, também, pela relação candidato/vaga dos exames de admissão nos anos 1950. Em 1955, o número de candidatos inscritos no processo seletivo foi de 128; em 1956, de 217; e em 1957, de 179. Nos três anos, os candidatos concorreram a 80 vagas, sendo, portanto, o número de inscritos muito superior ao de vagas oferecidas pela instituição (Escola..., 1955, 1956; Escola..., 1957).

O crescimento da demanda que se observa a partir da década de 1950 representou uma tendência geral ocorrida nos estabelecimentos da rede federal de ensino agrícola. Na mesma década, a frequência nos exames vestibulares nesses estabelecimentos foi muito maior que o número de vagas disponíveis. A restrição do número de vagas ocorria em virtude da limitada capacidade dos dormitórios ou alojamentos dos estabelecimentos (Brasil. Ministério da Agricultura, 1953).

Quanto ao local de origem, a maioria dos alunos internados na instituição vinha de diferentes municípios do interior do estado de Sergipe. Ressalte-se que alunos procedentes de municípios dos estados de Alagoas 
e Bahia também foram matriculados no internato. Aqueles oriundos dos municípios do interior do estado de Sergipe predominaram; mas a capital, Aracaju, desde a década de 1930, despontou com uma relativa importância no envio de alunos para o internato, embora muitos desses fossem provenientes de famílias que migravam do interior para a capital em busca de trabalho ou estudo para os seus filhos (Brasil. Ministério da Agricultura, 1938b; Escola..., 1955, 1957; Santos, A. G., 2006).

\section{Considerações finais}

No contexto do ensino agrícola federal, o internato existiu para corresponder às razões práticas das escolas agrícolas, às peculiaridades do ensino agrícola e ao atendimento de uma clientela específica. Nesse sentido, a localização espacial na zona rural da instituição pesquisada, distante das residências dos alunos e de difícil acesso por causa das dificuldades de transporte da época, foi um fator determinante para a adoção do regime de internato. Por outro lado, a assistência no internato garantiu o acesso e a permanência da clientela predominantemente pobre e de procedência rural que recorria ao estabelecimento. O internamento foi um regime utilizado, também, para dar efetividade à instrução prática dos internos na execução rotineira de tarefas agrícolas nos diversos núcleos agropecuários do estabelecimento, pois permitia a permanência em tempo integral na escola.

Na prática, o atendimento prestado pelo internato público e gratuito (residência, alimentação, enxoval, assistência médico-odontológica etc.) determinou na história da instituição uma dupla atuação: formação profissional agrícola e assistência integral aos seus alunos. Principalmente nas décadas de 1930 e 1940, o internato foi o grande atrativo para as famílias pobres que, além da instrução para os seus filhos, viam a escola como uma forma de sustento material para estes. Contudo, a origem predominantemente pobre dos sujeitos atendidos no internato sofreu uma variação no início dos anos 1950, motivada pelo ingresso de alunos procedentes das camadas médias da população em busca dos cursos ginasial e colegial e por uma formação profissional técnica agrícola de nível médio que a instituição passou a disponibilizar.

A pobreza e a procedência interiorana da maioria dos internos eram fatores que facilitavam a adaptação à rotina de tarefas práticas nos núcleos agropecuários e a conformação aos rigores disciplinares do internato. Estes estavam acostumados ao trabalho, pois ajudavam a família na execução de tarefas agrícolas. Procediam de famílias rurícolas pobres, cujas condições de sobrevivência e oportunidades de estudo nos locais onde habitavam eram difíceis ou muitas vezes inexistentes. Assim, transparece no decorrer do período pesquisado, especialmente da década de 1930 a meados de 1950, uma dualidade de atuação da escola: a formação profissional agrícola e o assistencialismo mediante o internato público e gratuito. 
Referências bibliográficas

AGROTÉCNICA não tem vagas. A Cruzada, Aracaju, p. 1, 11 fev. 1967.

BANDEIRA, A. R. P. Um agrônomo no ensino agrícola do Nordeste.

Fortaleza: [s.n.], 1989.

BARROS, C. de O. [Entrevista]. [S. 1]: [s. n.], 2006. Concedida ao autor em 9 de outubro de 2006.

BOSI, E. Memória e sociedade: lembranças de velhos. São Paulo:

Companhia das Letras, 1994.

BRASIL. Decreto n ${ }^{\circ} 23.722$, de 09 de janeiro de 1934. Transfere para o Ministério da Agricultura serviços agrícolas regionais dos Estados de Sergipe, Pernambuco e Alagoas, abre crédito para o respectivo custeio e dá outras providências. Diário Oficial da União, Rio de Janeiro, 9 jan. 1934a.

BRASIL. Decreto $\mathrm{n}^{\circ} 24.115$, de 12 de abril de 1934. Dispõe sobre a organização definitiva dos estabelecimentos de ensino elementar de agricultura, subordinada à diretoria do ensino agrícola, do Departamento Nacional da Produção Vegetal, e dá outras providências. Diário Oficial da União, Rio de Janeiro, 12 abr. 1934b.

BRASIL. Decreto $n^{\circ} 14.252$, de 10 de dezembro de 1943. Aprova o regimento dos Aprendizados Agrícolas. Diário Oficial da União, Rio de Janeiro, 10 dez. 1943.

BRASIL. Decreto $\mathrm{n}^{\circ} 22.506$, de 22 de janeiro de 1947. Altera a denominação de estabelecimentos de ensino agrícola, subordinados ao Ministério da Agricultura. Diário Oficial da União, Rio de Janeiro, 22 jan. 1947.

BRASIL. Decreto $n^{\circ}$ 31.533, de 2 de outubro de 1952. Transforma em Escola Agrícola a Escola de Iniciação Agrícola "Benjamin Constant" a que se refere o artigo 3 do decreto 22.506 de 22/01/1947. Diário Oficial da União, Rio de Janeiro, 2 out. 1952.

BRASIL. Decreto no 53.558, de 13 de fevereiro de 1964. Altera denominação de Escolas de Iniciação Agrícola, Agrícolas e Agrotécnicas. Diário Oficial da União, Brasília, 13 fev. 1964.

BRASIL. Decreto ${ }^{\circ}$ 60.731, de 19 de maio de 1967. Transfere para o Ministério da Educação e Cultura os órgãos de ensino do Ministério da 
Agricultura e dá outras providências. Diário Oficial da União, Brasília, DF, 22 maio 1967. Seção 1, p. 5543. Disponível em <http://www.senado. gov.br/sicon>.

BRASIL. Decreto-Lei n ${ }^{1.029}$, de 06 de janeiro de 1939. Dá denominações aos Aprendizados Agrícolas do Ministério da Agricultura. Diário Oficial da União, Rio de Janeiro, 6 jan. 1939.

BRASIL. Decreto-Lei n ${ }^{\circ}$ 9.613, de 20 de agosto de 1946. Lei Orgânica do Ensino Agrícola. Diário Oficial da União, Rio de Janeiro, 20 ago. 1946.

BRASIL. Lei $\mathrm{n}^{\circ}$ 4.024, de 20 de dezembro de 1961. Fixa as Diretrizes e Bases da Educação Nacional.Diário Oficial da União, [Rio de Janeiro], 27 dez. 1961.

BRASIL. Ministério da Agricultura. Aprendizado Agrícola de Sergipe. Livro das impressões dos visitantes. São Cristóvão: [s. n], 1935.

BRASIL. Ministério da Agricultura. Relatório das atividades do Ministério da Agricultura, durante o período de julho de 1934 a dezembro de 1935. Rio de Janeiro: Diretoria de Estatística da Produção, 1938a.

BRASIL. Ministério da Agricultura. Aprendizado Agrícola de Sergipe. Livro de matrícula do Aprendizado Agrícola de Sergipe. São Cristóvão: [s. n.], 1938b.

BRASIL. Ministério da Agricultura. Ministério da Agricultura: trabalhos realizados em 1938. Rio de Janeiro: Serviço de Publicidade Agrícola, 1939.

BRASIL. Ministério da Agricultura. Atividades do Ministério da Agricultura em 1952. Rio de Janeiro: Serviço de Informação Agrícola, 1953.

CERTEAU, M. de. A escrita da história. Rio de Janeiro: Forense Universitária, 2002.

CONCEIÇÃO, J. T. da. A pedagogia de internar: uma abordagem das práticas culturais do internato da Escola Agrotécnica Federal de São Cristóvão - SE (1934-1967). 2007. 213 f. Dissertação (Mestrado em Educação) - Universidade Federal de Sergipe, São Cristóvão, 2007.

ESCOLA AGRÍCOLA BENJAMIN CONSTANT. Relatório anual de atividades. São Cristóvão: [s. n.], 1955.

ESCOLA AGRÍCOLA BENJAMIN CONSTANT. Relatório anual de atividades. São Cristóvão: [s. n.], 1956. 
ESCOLA AGROTÉCNICA BENJAMIN CONSTANT. Relatório anual de atividades. São Cristóvão: [s. n.], 1957.

GREGÓRIO, J. [Entrevista]. [S. 1.]: [s. n], 2005. Concedida ao autor em 16 de novembro de 2005.

LE GOFF, J. História e memória. Campinas: Ed. UNICAMP, 2003.

MENDONÇA, N. Análise quantitativa e qualitativa do Sistema

Educacional do Estado de Sergipe. Aracaju: Biblioteca E. Dória, 1959.

Datilografado.

MENDONÇA, S. R. de. O ruralismo brasileiro. São Paulo: Hucitec, 1997.

MORAES, D. de. Rumo ao campo. In: COSTA, M. J. F. F. da; SHENA, D. R.; SCHMIT, M. A. (Org.). CONFERENNCIA NACIONAL DE EDUCAÇÃO,

1., 1927, Curitiba. Anais... Brasília, DF: SEDEIA/Inep/IPARDES, 1997.

p. 194-196.

NAGLE, J. Educação e sociedade na Primeira República. Rio de Janeiro: Fundação Nacional de Material Escolar, 1974.

NASCIMENTO, J. C. do. Memórias do aprendizado: oitenta anos de ensino agrícola. Maceió: Edições Catavento, 2004.

NERY, M. A. A. M. A regeneração da infância pobre sergipana no início do século XX: o Patronato Agrícola de Sergipe e suas práticas educativas. 2006. Dissertação (Mestrado em Educação) - Núcleo de Pós-Graduação em Educação, Universidade Federal de Sergipe, São Cristóvão, 2006.

NUNES, C. História da educação brasileira: novas abordagens de velhos objetos. Teoria e Educação, Porto Alegre, n. 6, p. 151-182, 1992.

OLIVEIRA, M. R. P. de. Formar cidadãos úteis: os Patronatos Agrícolas e a infância pobre na Primeira República. Bragança Paulista: Universidade São Francisco, 2003.

RAMOS, J. [Entrevista]. [Aracaju]: [s. n.], 2005. Concedida em 30 de novembro de 2005.

SANTOS, A. G. dos. [Entrevista]. [Aracaju]: [s. n.], 2006. Concedida em 3 de maio de 2006.

SANTOS, A. V. [Entrevista]. [Aracaju]: [s. n.], 2006. Concedida em 13 de setembro de 2006. 
SANTOS, J. C. dos. [Entrevista]. [Aracaju]: [s. n.], 2006. Concedida em 20 de setembro de 2006.

SANTOS, M. do C. [Entrevista]. [Aracaju]: [s. n.], 2005. Concedida em 23 de novembro de 2005.

SANTOS, R. J. dos S. [Entrevista]. [Aracaju]: [s. n.], 2005. Concedida em 18 de novembro de 2005.

SERGIPE. Arquivo Geral do Poder Judiciário do Estado de Sergipe. Instrucções e formalidades para a matrícula de menores nos aprendizados agrícolas. Aracaju: Juizado da Infância e da Juventude, 1938.

SERGIPE. Arquivo Geral do Poder Judiciário do Estado de Sergipe. Inquérito (SCR/C. 2906). Aracaju: [s. n.], 1953.

SOUZA, R. de F. de. Templos de civilização: a implantação da escola primária graduada no Estado de São Paulo (1890-1910). São Paulo: Unesp, 1998.

TÔRRES FILHO, A. O ensino agrícola no Brasil. Rio de Janeiro: Imprensa Nacional, 1926.

TORRES FILHO, A. Desenvolvimento do ensino agrícola no Brasil. Revista Brasileira de Estudos Pedagógicos, Rio de Janeiro, v. 17, n. 46, p. 117-121, abr./jun. 1952.

ZIBAS, D. M. L. Internato: umas das faces ocultas do ensino agrícola de $2^{\circ}$ grau. Cadernos de Pesquisa: Revista de Estudos e Pesquisa em Educação, São Paulo, n. 62, p. 45-51, ago. 1987.

Recebido em 12 de novembro de 2014.

Solicitação de correções em 27 de maio de 2015.

Aprovado em 22 de junho de 2015. 